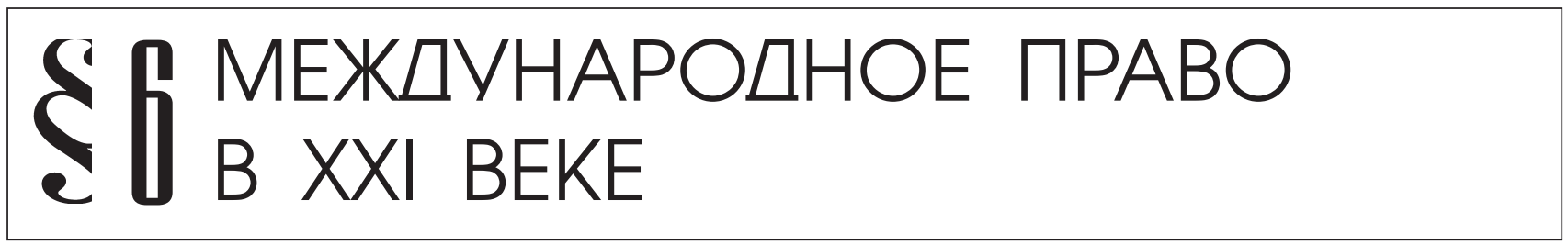

\title{
К ИСТОКАМ КОНЦЕПЦИИ «ОТВЕТСТВЕННОСТИ ПО ЗАЩИТЕ»: АНАЛИЗ ПОЛИТИКО-ПРАВОВЫХ АСПЕКТОВ ДОКЛАДА МЕЖДУНАРОДНОЙ КОМИССИИ ПО ВМЕШАТЕЛЬСТВУ И ГОСУДАРСТВЕННОМУ СУВЕРЕНИТЕТУ
}

Аннотация: Предметом исследования является кониепиия «ответственности по зашите», основные положения которой содержатся в ее базовом документе - Докладе Международной комиссии по вмешательству и государственному суверенитету (МКВГС) (2002). Значительное внимание уделено таким компонентам кониепции «ответственности по защите», как ответственность по реагированию, ответственность по предотвращению гуманитарной катастрофы и по восстановлению после событий. Анализу подверглись основные критерии принудительного вмешательства, в частности: надлежашче полномочия, справедливое дело, благое намерение, последнее средство, соразмерность, вероятность успеха. Методы исследования: системного анализа, синтеза, аналогии, классификации, исторический, сравнительно-правовой, систематический, структурно-функииональньй, формально-логический, лингвистический, специиально-юридический, Совокупность используемой методологической базы позволила гарантировать в итоге достоверность и обоснованность полученных выводов. Новизна работы заключается в выявлении автором того факта, что при первом своем обосновании данная концепция заложила основу для правовой коллизии по отношению к цуелому ряду основополагаюших норм и принципов современного международного права. По результатам анализа автор приходит к выводу, что концепция «ответственности по защчите» изначально содержала потенциальную попытку пересмотра целого ряда норм и принципов международного права, ревизии положений Устава ООН и деятельности самой Всемирной организации.

Ключевые слова: Организация Объединенных Наџий, Совет Безопасности ООН, НАТО, ответственность по защите, правовая норма, критерии, конщепция, МКВГС, полномочия, соразмерность.

Abstract: The subject of this research is the concept of "The Responsibility to Protect", the main positions of which are contained in its primary document - the report of International Commission on Intervention and State Sovereignty (ICISS) (2002). A significant attention is given to such components of the concept "The Responsibility to Protect" as responsibility to respond, responsibility to prevent humanitarian crises, and restoration afterwards. Analysis is conducted on the key criteria for forced intervention, including: right authority, just cause, right intention, last resort, proportional means, and reasonable prospects. The scientific novelty consists in the author's revelation of the fact that this concept laid the foundation for conflict of laws with regards to a number of fundamental norms and principles of modern international law. As a result of the analysis the author comes to a conclusion that the concept of "The Responsibility to Protect" a priori contained a potential attempt to review a number of norms and principles of international law, and revise the positions of the UN Charter and work of this global organization.

Keywords: Unite Nations, UN Security Council, NATO, Responsibility to protect, Legal norm, Criteria, Concept, ICISS, Authority, Proportionality.

равовые принципы и механизмы ООН и основанная на них система поддержания и сохранения международного мира и безопасности составляют, по всеобщему признанию, потенциально эффективный механизм обеспечения международной безопасности и мирового правопорядка. Вместе с тем, эта система не лишена ряда недостатков и противоречий. В частности, одним из неоднозначных вопросов является т.н. концепция «ответственности по защите», которая содержит определенный «коллизионный по- 
тенциал» в отношении, как международного права, так и всей системы международных отношений. Как представляется, в целях поиска возможных «развязок» было бы целесообразным вернуться к истокам концепции «ответственности по защите» и проанализировать ее базовый документ - Доклад Международной комиссии по вмешательству и государственному суверенитету (2002).

Прежде всего, важно подчеркнуть, что главная идея данного документа сводится к следующему постулату: «ответственность по защите признает, что первейшая обязанность в этой связи лежит на конкретном государстве и что только в случае, если государство не способно или не желает осуществлять такую ответственность или само виновато в создавшейся ситуации, она становится ответственностью международного сообщества, которое будет действовать вместо этого государства» [2].

Существенным недостатком данной концепции является то, что ее правовой статус сформулирован достаточно размыто: она названа «связующей концепцией, заполняющей разрыв между вмешательством и суверенитетом» [2].

Авторы доклада выделили три компонента концепции «ответственности по защите»: наряду с ответственностью по реагированию, она должна была включать ответственность по предотвращ⿻ению гуманитарной катастрофы и по восстановлению после событий.

Среди названных в концепции мер прямого предотвращения конфликта - меры дипломатические и политические (в том числе применение политических санкций, дипломатическая изоляция), экономические и правовые (в частности, размещение наблюдателей), а также военные (в том числе согласованное превентивное развертывание войск и угроза применения силы).

По сути, концепция с неясным политическим характером уже в данном документе становится обоснованием для целого комплекса многообразных мер дипломатического, правового и военного характера. Однако в документе мягко обходится вопрос правового обоснования действий: в нем указывается только, что «в каждом случае переход от мер побуждения <.. > к более интрузивным и принудительным < . > мерам < . > имеет большое значение, и его нельзя предпринимать без тщательного обдумывания» [2]. Подчеркнем, речь не идет о сколько-то основательно юридической базе или четком механизме по ее имплементации, а лишь о субъективном процессе «обдумывания».

В данном документе довольно четко прослеживается насильственный характер возможных для применения мер, который, по сути, проявляется в виде завуалированной угрозы. Она, в частности, содержится в следующей фразе: «...некоторые государства вообще неохотно соглашаются на поддержанные международным сообществом превентивные меры, даже наиболее мягкие»; в Докладе рекомендуется «признавать, что многие превентивные меры по сути своей являются принудительными и интрузивными»; также говорится о том, что государства, сопротивляющиеся усилиям по помощи извне, «вполне могут < ..> увеличить риск более сильного нажима внешних сил, применения более жестких мер принуждения и, как крайняя мера, военного вмешательства извне» [2]. Очевидно, что, несмотря на декларирование принципа признания и уважения суверенитета и территориальной целостности затронутых стран, пока речь идет о сугубо силовом сценарии решения возможных проблем гуманитарного характера. При этом речь не идет об сколь-нибудь серьезном юридическом обосновании возможного вмешательства во внутренние дела государства-объекта «ответственности по защите».

Вместе с тем, в Докладе признается, что концепция «ответственности по защите» предполагает, прежде всего, ответственность по реагированию «в ситуациях, когда настоятельно необходимо защитить людей» [2]. Меры интервенционистского характера в таком случае могут включать политические, экономические, судебные и, «только в исключительных случаях», военные акции: «...до применения более жестких и принудительных и интрузивных мер следует всегда рассматривать возможность применения мер менее интрузивного и менее принудительного характера» [2].

При этом «жесткие пороговые условия», служащие обоснованием для военного вмешательства, определяются пока только описательно: «...для оправдания военной акции положение должно быть действительно тяжелым» [2]. Очевидно, что никаких юридических оснований для имплементации концепции также отсутствуют в данном документе.

В качестве отправного пункта для принятия решения о военной акции авторы Доклада предлагают выбрать принцип невмешательства. Однако в исключительных обстоятельствах, при проявлениях насилия, которые «глубоко возмущают совесть человечества» или представляют собой очевидную и реальную угрозу мировой безопасности, принимается решение о принудительном вмешательстве.

В документе обозначены и охарактеризованы шесть критериев такого вмешательства. Обратимся к их анализу с целью исследования их юридической природы и возможности их применения 
DOI: $10.7256 / 1811-9018.2015 .9 .16219$

При цитировании этой статьи сноска на dоі обязательна

\section{Право и политика $9(189) \cdot 2015$}

\section{1. Надлежащие полномочия.}

Полномочия по предоставлению санкций по урегулированию проблем, касающихся международного мира и безопасности «переданы от великих держав, всех вместе, Организации Объединенных Наций» [2]. Наиболее авторитетным органом является Совет Безопасности ООН, и именно он назван в документе единственным органом, имеющим легитимную силу и полномочия для принятия решения по применению принудительных мер по поддержанию международного мира и безопасности В этой связи авторы документа призывают Совет Безопасности действовать более решительно и эффективно: «Крайне важно предпринять все усилия для того, чтобы склонить Совет безопасности осуществлять свою ответственность по защите, а не отказываться от нее» [2].

\section{2. Справедливое дело.}

Военное вмешательство, по мнению Комиссии, оправдано при наличии следующих двух больших групп обстоятельств:

а) крупномасштабные человеческие жертвы, фактические или в высшей степени вероятные, связанные или не связанные с геноцидом, как результат либо преднамеренных действий государства, либо его бездействия или неспособности действовать, либо паралича государственной власти;

б) крупномасштабные «этнические чистки», фактические или в высшей степени вероятные, осуществляемые путем убийства людей насильственно вытеснения с обычных мест проживания, актов террора или изнасилования [2].

В Докладе говорится далее: «Если одно или оба эти условия присутствуют, то нам представляется, что компонент критерия «справедливое дело» решения о вмешательстве наличествует в полном объеме». Здесь же оговаривается правомочность, с позиций авторов документа, превентивных военных действий: «...мы четко заявляем о том, что военная акция может быть правомерной в качестве упреждающего действия в ответ на явное свидетельство вероятных крупномасштабных убийств. Без такой возможности предпринять упреждающее действие международное сообщество будет поставлено в морально несостоятельное положение, когда ему требуется подождать, пока начнется геноцид, прежде чем оно сможет предпринять действия по его прекращению» [2].

Очевидно, что без четкого определения понятия «крупномасштабное» (по отношению к употребляемым понятиям «убийство», «геноцид», «жертвы», «злоде- яние») подобное утверждение права на превентивное военное вмешательство выглядит необоснованным, несостоятельным в правовом отношении, несмотря на все глубокое гуманитарное содержание.

Вместе с тем, в Докладе зафиксирован отказ от применения военного вмешательства в рамках концепции «ответственности по защите»в отношении тех случаев, когда допускаются нарушения прав человека, не связанные напрямую с массовыми убийствами или этническими чистками: расовая дискриминация, систематические аресты, репрессии в отношении политических оппонентов, свержение демократического правительства, спасение государством своих граждан на иностранной территории. Таким образом, основания для применения вышеупомянутой концепции ограничиваются, относительно выдвигавшихся ранее оснований для обоснования права на гуманитарную интервенцию.

В Докладе не содержится каких-либо указаний на органы, которые могли бы определять степень опасности сложившейся ситуации, чтобы оправдать критерий «справедливое дело»; указано, что на эту роль мог бы претендовать Международный комитет Красного Креста, однако в силу понятных причин он не желает иметь отношения к политическим решениям.

В Докладе содержится рекомендация Генеральному секретарю или Совету Безопасности ООН направлять независимую специальную миссию по установлению фактов с целью получить достоверную оценку ситуации.

Таким образом, критерий справедливого дела имеет в документе описательные характеристики, определяемые через понятия крупномасштабных человеческих жертв и этнических чисток; определение масштабов и оснований для реагирования международного сообщества ложится на ситуативно определяемые подразделения ООН.

\section{3. Благое намерение.}

Критерий благого намерения определяется авторами документа через намерение прекратить или предотвратить страдания людей. Этому критерию не соответствуют, в частности, такие цели, как изменение границ или поддержка одного из режимов.

Соблюдение данного критерия предполагает соответствие ситуации трем условиям:

а) чтобы военное вмешательство всегда осуществлялось на коллективной или многосторонней, а не односторонней основе; 
б) чтобы население, во благо которого предполагается осуществить вмешательство, поддерживало эту идею в действительности;

в) чтобы вмешательство было поддерживаемо другими странами [2].

При всей гуманитарной ценности ведущего критерия, названные условия оказываются в определенной мере сложно измеримыми, особенно в ситуации превентивных мер.

\section{4. Последнее средство.}

Ключевым в описании данного критерия становится следующий постулат: «Ответственность по реагированию (с принудительным военным вмешательством) может быть оправдана только в том случае, если в полном объеме использована ответственность по предотвращению» [2], то есть требуется, чтобы военный путь урегулирования или предотвращения гуманитарного кризиса применялся после того, как исчерпаны все возможные дипломатические, экономические и судебные пути предотвращения. Вместе с тем. составители документа отдают себе отчет в том, что исчерпывающее использование средств невоенного урегулирование может занять очень много времени: «часто просто не хватит времени, чтобы исчерпать все варианты» [2]. Такая неполная определенность критерия последнего средства также свидетельствует о крайней расплывчатости возможного правового статуса концепции ответственности по защите, как и ее предлагаемых в документе аспектов - ответственности по предотвращению, реагированию и восстановлению.

\section{5. Соразмерность.}

При характеристике данного критерия приведены требования к масштабу применяемых военных действий: «Средства должны быть соразмерны целям и соответствовать масштабу первоначального действия, требующего реагирования» [2]. Оговорена также минимальная степень воздействия на политическую систему страны и строгое выполнение всех норм международного гуманитарного права.

Очевидно, что в последнем требовании заметна правовая коллизия: сама концепция «ответственность по защите», по сути, представляет собой попытку, как представляется, обосновать нарушения таких принципов международного права, как государственный суверенитет, принцип невмешательства, неприменения силы и других.
6. Вероятность успеха.

Последний критерий определяется через «обоснованный шанс достичь успеха, то есть прекращения или предотвращения жестокостей или страданий». Также указано, что «военное вмешательство не будет оправданным, если < .. > последствия вмешательства, совершенно очевидно, ухудшат ситуацию по сравнению с тем, если бы никаких действий не предпринималось вообще» [2].

Важно подчеркнуть, что при характеристике данного принципа допускается прямое признание в неравноправии различных государств относительно санкций ООН и Совета Безопасности Организации: «Из чисто утилитарных соображений применение данного принципа предосторожности, вероятно, исключит военную акцию против любого из пяти постоянных членов Совета Безопасности, даже если бы наличествовали все остальные условия для проведения акции вмешательства $<\ldots>$ То же относится и к другим крупным державам, не являющимися постоянными членами Совета Безопасности ...» [2]. Вмешательство в таком случае, утверждается в Докладе, приведет к более серьезным последствиям, нежели повод для вмешательства.

Данное соображение отвечает принципу невмешательства во внутренние дела государства, однако представляет собой одно из немногих замечаний, ограничивающих данную концепцию в политикоправововом смысле.

В тексте Доклада немало высказываний, подтверждающих неопределенность высказываемых концепций, критериев и условий. В частности, в отношении критерия соразмерности высказано замечание, которое может быть распространено на большое количество сложно дефинируемых понятий, используемых в документе: «Хотя в каждом конкретном случае можно спорить в отношении того, к каким конкретно последствиям приведут на практике эти ограничения, применяемые принципы достаточно очевидны» [2].

При этом важно отметить, что «очевидность» тех или иных принципов, как факторов применения мер военного реагирования, никак не может быть достаточным правовым обоснованием для внешней интервенции в границы суверенного государства. Основанием для формулировки и осуществления концепции «ответственности по защите» оказывается, в итоге, «международный идеализмом», носителем которого, наряду с политическим реализмом, является ООН.

Соображения по поводу ответственности по восстановлению, т.е. завершающей стадии вмешательства 
DOI: $10.7256 / 1811-9018.2015 .9 .16219$

При цитировании этой статьи сноска на dоі обязательна

\section{Право и политика 9 (189) • 2015}

в дела государства, также носят в Докладе рекомендательный характер, определяя соотношение предлагаемых максим с таким, в частности, принципом, как государственный суверенитет.

Отечественный исследователь В.С. Котляр подчеркивает, рассматривая концепцию «ответственности по защите» в качестве оправдания НАТО фактически своей гуманитарной интервенции против Югославии, что комиссия Эванса-Сахнуна предлагает довольно сбалансированную концепцию гуманитарной интервенции: с одной стороны, государствам дают понять, что, в случае проведения ими, вопреки их конституциям, незаконных репрессий или силовых акций против групп собственного населения с массовыми жертвами международное сообщество может осуществить вмешательство, в том числе и вооруженное, во внутренние дела таких государств в гуманитарных целях, для исправления создавшегося положения. С другой стороны, понимая, что предлагаемая корректировка международно-правовых принципов невмешательства во внутренние дела государств может открыть широкие возможности для злоупотребления силой государствами в собственных эгоистических интересах, комиссия подчеркивает, что решение о вооруженной гуманитарной интервенции может быть принято только через $\mathrm{OOH}$, то есть согласно Уставу ООН, через ее Совет Безопасности [3].

В данном документе, таким образом, впервые в контексте концепции «ответственности по защите» предложена новая редакция статьи 2.7. Устава ООН, согласно которой определяются дела, входящие во внутреннюю компетенцию любого государства: «то, что входит «по существу дела во внутреннюю компетенцию», <..> на деле вызывает много споров, особенно в контексте проблем в области прав человека» [3]. Таким образом. гуманитарные основания становятся базисом для пересмотра постулатов международного права.
Вместе с тем, в качестве факторов легитимизации действий в рамках данной концепции в документе приводятся статьи 42 и 51 из Устава ООН. Здесь прямо заявляется о намерении и дается характеристика основаниям для имплементации основных положений концепции «ответственности по защите» в национальные системы права: указанные позиции в Уставе ООН в прямом смысле сводят на нет «ограничения, устанавливаемые внутренней юрисдикцией» [3].

Важно отметить, что в данном документе неслучайно содержится критика права вето пяти постоянным членов Совета Безопасности ООН. При этом авторы Доклада снова руководствуются гуманитарными соображениями: «несправедливо, что одно вето может перевесить мнение всего остального человечества по гуманитарным вопросам чрезвычайной значимости» [2]. Тем самым создатели концепции «ответственности по защите» подвергают сомнению давно сформированную практику применения права вето, которое является одной и прерогатив держав, играющих важную роль в поддержании международного мира и безопасности [1]. Так, в частности, в течение 2004-2012 годов Россия накладывала вето на резолюции по вопросам о положении на Кипре (S/2004/313), в Мьянме (S/2007/14), о мире и безопасности в Африке (Зимбабве) (S/2008/447), о положении в Грузии (S/2009/310) и на Ближнем Востоке (S/2011/612, S/2012/77, S/2012/538), что существенным образом влияло на мировую политику, ограждало суверенитет отдельных стран и территорий и в значительной мере способствовало поддержанию международного мира и безопасности.

Таким образом, уже при своем рождении концепция «ответственности по защите» содержала потенциальную попытку пересмотра целого ряда норм и принципов международного права, ревизии положений Устава ООН и деятельности самой Всемирной организации.

\section{Библиография:}

1. Вето в Совете Безопасности [Электронный ресурс]. Режим доступа: http://www.un.org/ru/sc/meetings/veto.

2. Доклад Международной комиссии по вмешательству и государственному суверенитету [Электронный ресурс]. Режим доступа: http://daccess-dds-ny.un.org/doc/UNDOC/GEN/N02/525/72/IMG/N0252572.pdf.

3. Котляр В.С. Концепция ответственности за защиту как проект кодекса проведения гуманитарных интервенций // Международное публичное и частное право. 2005. № 3. [Электронный ресурс]. Режим доступа: http://www.lawmix.ru/ $\mathrm{comm} / 776$.

References (transliterated):

1. Kotlyar V.S. Kontseptsiya otvetstvennosti za zashchitu kak proekt kodeksa provedeniya gumanitarnykh interventsii // Mezhdunarodnoe publichnoe i chastnoe pravo. 2005. № 3. [Elektronnyi resurs]. Rezhim dostupa: http://www.lawmix.ru/comm/776. 